\title{
The Truth and Reconciliation Commission and gender: The Testimony of Mrs Konile revisited
}

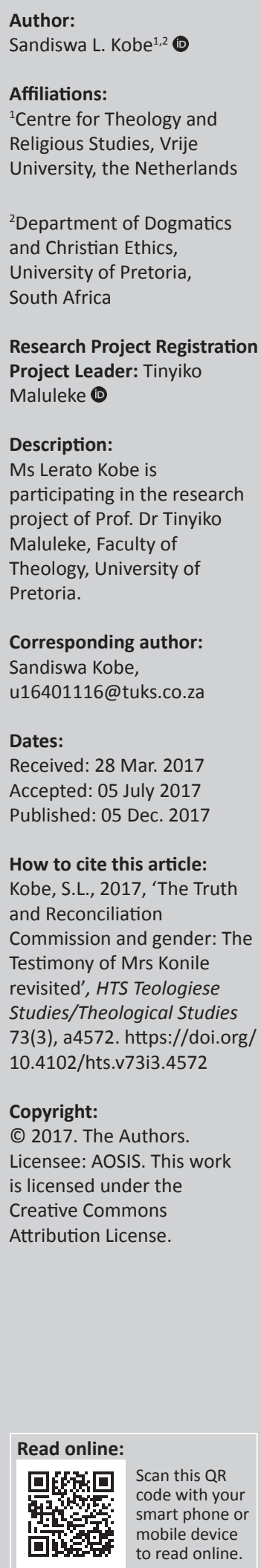

This article draws on a well-known narration of the Gugulethu Seven incident from the Truth and Reconciliation Commission (TRC) proceedings with specific reference to testimonies of the mothers of the Gugulethu Seven. The article focuses on Mrs Konile's testimony as a case study: Testimony of a black woman whose son was murdered by the apartheid government's security forces. During the TRC hearings, Mrs Konile 'failed' to effectively narrate her story, which resulted in her testimony being dismissed as being incoherent. This article examines the underlying attributes of Mrs Konile's testimony and revisits why she was considered 'incapable' of articulating her experience in a convincing manner. The analysis aims to acknowledge, identify and give insights about this woman's testimony from an African women theologian viewpoint (specifically with references to the Isixhosa religious cultural background).

\section{Introduction: Nature of the Truth and Reconciliation Commission}

Following the negotiated settlement reached in the period between 1990 and the first democratic elections in 1994, the South African Truth and Reconciliation Commission (TRC) was established in 1995 in order to address human rights violations committed during the apartheid period. ${ }^{1}$ The South African TRC followed the pattern of other commissions that had taken place before it; however, it added a distinct emphasis on the need for national reconciliation. Thus, it was established in terms of the Promotion of National Unity and Reconciliation Act, No. 34 of 1995. The work of the commission focused on the period from the Sharpeville massacre in March 1960 until 1994. The commission was established through the selection and appointment of 17 commissioners named in the Government Gazette in December 1995. Archbishop Desmond Mpilo Tutu was appointed as the chairperson, with Dr Alex Boraine as vice-chairperson. The work of the TRC was structured in the form of the following three committees:

The Human Rights Violations Committee investigated human rights abuses that occurred between 1960 and 1994; The Reparation and Rehabilitation Committee was charged with restoring victims' dignity and formulating proposals to assist with rehabilitation; The Amnesty Committee considered applications from individuals who applied for amnesty in accordance with the provisions of the Act. (Doxtader \& Salazar 2007:14-27)

\section{Truth Reconciliation Commission and gender}

At the beginning of the TRC of South Africa, Desmond Tutu announced that in the new democratic South Africa, everyone, everything, belongs. None are outsiders, all are insiders, and all belong. This view was Desmond Tutu's notion of a rainbow nation and the spirit of Ubuntu, which is described further in his book entitled, The Rainbow People of God: A Spiritual Journey from Apartheid to Freedom, (1994). Desmond Tutu called for Ubuntu, in order to build an inclusive society in the new South Africa. In his theology of reconciliation, he called for the importance of being human (Tutu 1999:279). He argued that Jesus came to re-establish friendship and community between humanity and God, between human beings and between human kind and the rest of creation. And so, among many other things, the tasks of the TRC of South Africa were to listen to both perpetrators and victims of gross human rights violations. This meant that the TRC had to include the stories of both men and women in its constructive interaction with human rights violations. To do this, the TRC held discussions with civil society concerning both the gendering of apartheid and the gendered aspects of the experiences of human rights abuses during the apartheid period. This was considered as a positive initiative by many gender justice activists.

1.The African National Congress wanted a 'Truth Commission' that is similar to the ones I have mentioned above. On the other side, the National Party wanted a 'Reconciliation Commission'. The perpetrators group was concerned about the victims of apartheid, and the victims were looking for amnesty for the perpetrators; that is how the term 'Truth and Reconciliation Commission' came about (see Vorster 2004:497-498). 
However, debates held before the TRC proceedings show that there were misunderstandings concerning gender: for example, Ilze Olckers (1996:62) argues that the male norm and the male experience remained the unacknowledged standard or dominant point of view'. Meintjes (2004:101) emphasises this point by arguing that the TRC tended to hypothesise gender as the experience of women (usually understood in relation to rape) rather than gender as relation to structure. It is argued that gender activists argued that if the TRC continued in this approach, the outcome will be the prohibiting of women's experiences and roles, stereotyping and rendering them invisible. Gender activists argued that such distorted recording of history will in fact be participating in perpetuating women's suffering and oppression. Gender activists argued that gender needs to be understood as a term that enables a careful understanding of how different women and men experienced apartheid (Olckers 1996:64). ${ }^{2}$ Meintjes (2004:101) argues that gross human rights violations had impacted men and women differently.

Engaging with the TRC of South Africa, some scholars have argued that it is in fact typical for processes such as the TRC to neglect gender justice. Mckay (2000:561-570) argues that TRC processes are usually driven by patriarchal interests that favour the powerful (male) and marginalise the women. ${ }^{3}$ The TRC's initiative to include gender justice was 'fatal' from the onset, and this is because under the guidelines of the legislation authorising the TRC, the TRC was mandated to only focus on victims of gross human rights abuses defined as 'killing', 'abduction', 'torture' or 'severe ill treatment' of any person by a person acting with political motive. This limited mandate of the TRC of South Africa then meant that millions of ordinary people, especially women who suffered from the structural violence of apartheid and not victims under the above-mentioned narrow definition of gross violation could not receive recognition.

\section{The Truth and Reconciliation Commission's narrative structure}

It is argued that during the proceedings of the TRC of South Africa, the TRC's Human Violations Committee dictated the form of victims' narratives (Krog, Mpolweni \& Ratele 2009:85). While $60 \%$ of submissions made to the human rights committee were by women, the TRC portrayed women as secondary objects. In the document titled 'Women's Contributions to the South African TRC' (2005), GodoboMadikizela writes that during the TRC proceedings, women were circumspect in speaking about their own experiences of human rights violations. Godobo-Madikizela (2005:15) argues that the TRC's method was intentionally that women

2.In the above-mentioned paper, ilze Oickers reports on the meetings held by gender activists, feminist scholars, non-government organisations, in particular the Centre for Applied legal Studies in regards to women's participation in processes leading up to the TRC of South Africa.

3.Mckay (2000:561) suggests that religious sources often view forgiveness as neka (2005:561) suggests that religious sources often view forgiveness as forgiveness, reconciliation and justice, an to take place in Mck (2000:561) suggests that both the religious source Mckay (2000:561) suggests that both the religious sources and the secular sources have one thing in common and that is the patriarchal assumptions that underlie their lack of discussion of gendered dimensions of justice and reconciliation. communicate on behalf of others, and this was described as a relational element of public testimonies. Women were to take on the duty of speaking out in order to engage others and on behalf of others.

The TRC's narrative logic was that women who were victims of gross human rights violations were to follow the following method:

The TRC victim's narrative was that victims should give biographical details, which then leads to the middle part of the testimony about the circumstances and content of the violation, thereafter the desire and needs of the victim would be established, after this establishment then the commissioner who was chairing that specific evidence gathering would conclude the interaction. (Krog 2007:191)

Victims such as Mrs Konile, who this article centres on, when testifying at the TRC human rights hearings were expected to follow such a victim narrative structure. However, Mrs Konile did not follow this narrative; instead, she concentrated more on her own personal experiences and suffering under the apartheid government. This article suggests that this then led to her testimony being declared incoherent by the TRC of South Africa.

\section{Principles of interpreting Mrs Konile}

Mrs Konile forms part of the testimonies of the four Gugulethu Seven mothers who became important figures in the TRC proceedings as their testimonies reintroduced the language of reconciliation and forgiveness in the South African society. Krog et al. (2009:9) write that the TRC itself used the words of the Gugulethu Seven mothers in its report when referring to reconciliation. However, it is only three Gugulethu Seven mothers whose words are featured, namely Mrs Cynthia Ngewe, Mrs Irene Mnxinwa and Eunice Thembisa Miya.

Mrs Konile's does not appear in the TRC reports. As mentioned above, during the TRC hearings, Mrs Konile 'failed' to effectively narrate her story, which resulted in her testimony being dismissed as being incoherent. Therefore, this article examines the underlying attributes of Mrs Konile's testimony and revisits why she was considered 'incapable' of articulating her experience in a convincing manner.

Antjie Krog points out that Mrs Konile's testimony was one of the most incoherent testimonies she had to report on as a journalist. The testimony indicated deeper psychological problems so that Krog had to ask herself if the puzzling aspects on Mrs Konile's testimony were purely cultural, or was she mentally disturbed, or was it that she (meaning Antjie Krog) had some vestiges of racism in her (see Krog et al. 2009:39). Antjie Krog claims that Mrs Konile's testimony strengthened racist views that the South African truth commission was successful in deconstructing, and this was one of 'the problems that Mrs Konile's testimony posed for people brought up and educated within racist system and ideology' (Krog et al. 2009:40). 
Nevertheless, the article focuses on Mrs Konile because of her refusal to forgive and reconcile with perpetrators of gross human rights violations during the proceedings of the TRC of South Africa (Krog et al. 2009:73). Mrs Konile was so alienated by the TRC processes that she was not able to speak to the processes and the processes were not able to get through to her. Mrs Konile's interventions, her experiences, her disposition, her orientation and her worldview exposed the weaknesses of the TRC testimony model at least for her and for others such as Mrs Hani who also refused to forgive perpetrators.

The aim of this article is to reflect on Mrs Konile's testimony from the perspectives offered by the Circle for Concerned African Women theologians (Circle). The circle is a community of African women theologians who come together to reflect on what it means to them to be women of faith within religion, culture, politics and social economic structures in Africa. Isabel Apawo Phiri (2005) writes that:

the circle seeks to build capacity of African women theologians to contribute their critical thinking and analysis to advance current knowledge using a theoretical framework based on theology, religion, and culture. (p. 1)

She argues that the circle also empowers African women to actively work for social justice in their own communities and reflect their actions in their own publications. The task of the circle is to voice their views against patriarchy and to liberate women's voices from oppression and discrimination. Thus, this article is written from my own viewpoint of the IsiXhosa religious culture, to articulate and give insights of Mrs Konile's testimony and thereby give voice to her suffering and experiences under the apartheid system as an African black woman.

Given the above-mentioned unwillingness of the TRC to give voice to women's experiences under the apartheid system, the article seeks to identify and give voice to Mrs Konile's suffering and experiences under the apartheid system.

\section{Context and circumstances of Mrs Konile's Testimony}

Based on what was seemingly an unintelligible testimony on the TRC website, Anjie Krog, Nosisi Mpolweni and Kopano Ratele agreed to conduct a closer investigation of Mrs Konile's testimony. In 2009, they published Mrs Konile's testimony in a book arguing that when they explored Mrs Konile's words from the archives coming from the proceedings of the TRC, they discovered that from the first words Mrs Konile uttered at the human rights hearings, her words got lost in translation. The translator failed to interpret Mrs Konile's words. From the testimony on the website, Mrs Konile began by saying 'I am Ms Khonele [sic] from (indistinct) I have three children [...] etc' (Krog et al. 2009:52).

In the testimony from the website (which is written in English), the transcriber misspelled Mrs Konile's name and wrote 'Khonele' instead of 'Konile'.
The word indicated by 'indistinct' was not known. And this part had a very negative effect on Mrs Konile's testimony. This is because (indistinct) was to describe the place from which Mrs Konile was from.

Krog, Ratele, Mpolweni argue that when they listened to the Isixhosa version of the testimony, they realised that 'indistinct' word was 'Indwe', a village in the Eastern Cape. And because this information was missing, Mrs Konile's audience had assumed that because the hearings were held in Cape Town, and the Gugulethu incident happened in Cape Town, and all the other three mothers who testified before her were from Cape Town, Mrs Konile was also from Cape Town. The audience had assumed that the word (indistinct) meant 'Cape Town'. So, when they realised that Mrs Konile was from the village in the Eastern Cape, this information significantly changed the whole narrative.

Possibly, it could be argued that the name spelling of Mrs Konile's name had no implications on her testimony. However, the assumption about where Mrs Konile was coming from had huge implications in distorting facts and even hearing Mrs Konile's testimony. This will be shown in the discussions below.

\section{The Method}

As Anjtie Krog's student at the University of the Western Cape (in 2013), I had the opportunity to discuss with her some of the challenges that faced the TRC of South Africa. In her classes, we were required to acknowledge the work of the TRC and to critique its work and mandate especially with regards to national reconciliation. 'There was this goat: Investigating the Truth and Reconciliation Commission Testimony of Notrose Nobomvu Konile' (2009), which was one of the books we were to use to critic and analyse the proceedings of the TRC. As a student, I was intrigued by Mrs Konile's testimony, so I asked Krog if there is any possibility to get the audio version of Mrs Konile's testimony. She offered the original Isixhosa version of the testimony and suggested that I should search the archives for video footage. In 2014, I decided to listen to the audio of original testimonies of the Gugulethu mothers. Watching the video of the testimonies, I decided to retranslate the testimony of Mrs Konile, and I reviewed the testimony in the light of IsiXhosa religion and culture. Mrs Konile's testimony was deeply influenced by the Isixhosa religion and culture.

Isixhosa religion and culture here should be understood in terms of African Traditional Religion (ATR). In her testimony, Mrs Konile uses symbols that are found within ATR; for example, dreams are very important in ATR. Ancestors are believed to communicate through dreams. I use Isixhosa religious culture in this article, and not simple ATR, so that I can give the meaning and significance of the symbols that Mrs Konile uses in her testimony that are based within the particular Isixhosa sociocultural background. 


\section{Mrs Konile's testimony: Scene one: Land inheritance (Ukucanda)}

My name is Mrs Konile from eNdwe. I had four children. The three daughters are all married, and the fourth one was the one who was shot. I was living with Zabonke, my son and depended on him. I had no husband; my husband had passed away earlier. ${ }^{4}$ Before Zabonke came to Cape Town, I and Zabonke were to inherit a piece of land (ukucanda). I had registered my son to inherit the land because women were not allowed to inherit land. After registration to inherit land, Zabonke told me he wanted to go to Cape Town to find work. Zabonke explained to me that he needs to go to Cape Town to find a job so we may be able to build when we inherit the land. When Zabonke arrived in Cape Town he indeed found work, he sent me money in the Eastern Cape. The time to issue land in the village had come, on the day I was supposed to get the piece of land I was denied access to land. 'All the other people's names except my name came out'. (See the video archive at the University of the Western Cape Island Museum Mayibuye Archived records)

It is already observed from the above discussion that the revelation of eNdwe as a place where Mrs Konile lived allows scholars to explore Mrs Konile's testimony in many other ways than focusing on what was perceived as inconsistent and incoherent. The knowledge about eNdwe gives to the reader free exploration of the text, and moreover the new knowledge demands its own ways of being comprehended. Therefore, I want to argue that Mrs Konile's testimony is logical. In my view, Mrs Konile was not only logical in her own right but also followed the TRC's narrative. If one reads carefully the first part of the testimony, one would realise that Mrs Konile answers the question posed to her by Dr Boraine (see the discussion below). However, in her following the TRC's narrative, she did it with a pinch of salt that allowed her to give voice to her own suffering and experiences under the apartheid system.

In simple terms, Mrs Konile disrupted the TRC narrative structure. Dr Boraine said to Mrs Konile:

Tell us where you come from, where you've been, and about your family before you tell us about what happened in 1986 .

Likewise, Mrs Konile responds to the question: 'My name is Mrs Konile, from eNdwe ...'. In the first part of the sentence, Mrs Konile pronounces her name, and where she is from, 'eNdwe'. In the following sentence, she mentions all her children by numbering them. She then goes into details, 'three were daughters and now all married, and she finishes the sentences by specifying Zabonke, as the fourth child, and the only son, who was shot'. She goes further and argues that she was living with Zabonke, and depended on him because her husband had passed away a long time ago. From this point, Mrs Konile digs deeper into where she comes from, where she has been, and about her family before saying something about 1986 as asked by Dr Boraine.

Here I want to argue, Mrs Konile spoke about what Zabonke meant to her as a mother living under the apartheid system. 4.After introducing herself as Zabonke's mother and confirming that indeed Zabonke
is her son, Mrs Konile goes further to depict for her audience what Zaboke meant in her life.
Indeed, looking at the first three women's testimonies, the audience expected that Mrs Konile will share some sentimentality about Zabonke. However, for Mrs Konile this was not what she had in mind, so she goes on and tells the audience that before Zabonke left for Cape Town, the villagers were going to give them a site to build. 'I had registered my son to inherit land because women were not allowed to inherit land'; however, Zabonke left before this was finalised. Mrs Konile argues that yes Zabonke did find a job in Cape Town and he supported me as I said I was depended on him. However, when the time to receive land came, I did not get the land 'all the other people's names came out, except mine'. I want to argue that Mrs Konile connects the land issue to the fact that she was a widow, a woman, and to the fact that Zabonke who was the man she registered herself under was not around in the village to speak for her. In this overarching analysis, Mrs Konile speaks about being a woman living under the apartheid system, about the difficulties of being a widow within the culture of Isixhosa, how she was not allowed within the Isixhosa culture to inherit land because she was a woman and how she was only someone when a male figure was around. ${ }^{5}$

Historically in African society, women used to perform $60 \%-80 \%$ of the agricultural labour. Letsoalo (1986:226) writes that long before the 'basic needs' concept became fashionable in the literature of development, African women produced food, provided water and clean clothing, taught children language and healthy habits and performed certain tasks and others in their communities. Letsoalo argues that in the modern society this might be described as the disproportionate division of labour, but in traditional African society this allowed African women to have access to a quality life in the broadest sense. She argues that this allowed African women to utilise valuable statuses and activities that constituted people's well-being and human flourishing. With the arrival of colonialism, industrialisation and the dawn of the apartheid era in South Africa, African black women in South Africa were left without any source of employment and survival. Black men had to find employment in the mines and industries. Women had to find ways to complement their husbands' migratory remittances in order for their families to survive. Then women were to be found working in two areas: one group in the rural ancestral regions confined by apartheid legislation (usually denied the right to be with their husbands, and worked in the rural farms), and others were found in what was called 'black urban areas' in the backyards of their white madams, etc. (Letsoalo 1986:226). ${ }^{6}$

Moreover, Letsoalo (1986:226) argues that the more racist a society was, the more sexist it became. The apartheid racial policy that discriminated against black people brought about

5.Apartheid had discriminated against her because of race, class, and gender. She was left to only be able to know her son as a means to an end. We notice this when Mrs Konile in the following paragraph she starts talking about land (Ukucanda). She Mrs Konile in the following paragraph she starts talking about land (Ukucanda). She elaborates the extent of her dependence on her son Zabonke by bringing up the
issues around inheritance of land.

6.The Changing role of Women in employment. By the way, this is how the Gugulethu Seven mothers are different from one another, the other three lived in the black Seven mothers are different from one another, the other three lived in the black
urban areas. It was either them working for the white madams, or their husbands. But Mrs Konile lived in the villages in the Eastern Cape. 
triple oppression for black women: they were discriminated against because of race, class and gender. The more racist South Africa was, the more sexist it became. For example, in the rural periphery, black women lag far behind black men in accessing the benefits of development. Black women without education were forced to work on the white farms and in apartheid-directed Bantustan industries, and women who had access to education were limited to work as teachers and nurses. The other group of women were forced to depend on their husbands, especially those who were Christians because the woman's place was in the kitchen and to raise children at home. ${ }^{7}$ Through the apartheid legislation, men were placed in a superior place and thereby black men became bread winners. This resulted in black women having to be subordinate to male figures to access development; male figures had already been practising patriarchy, which believed that culturally women cannot own land. This is where Mrs Konile finds herself as a rural black woman. Mrs Konile points out that when her son went to Cape Town, she did not receive land, while all others received their piece of land (see the translated testimony above). She articulates clearly how she found herself in a system of oppression and reflects on a patriarchal phenomenon of structural relationships in hierarchies and pyramids.

Imathiu (2001:29) writes that 'women are known as their father's daughters when unmarried, their husband's wives when married, and are also referred to as the mother of their firstborn child after motherhood'. Likewise, the IsiXhosa culture is not different.

I argue that Mrs Konile in this first scene asserts her will to arise in the new democratic South Africa. She voices out gender injustices in her own life. She relates gender to structures and how such structures determined her will to arise as a black woman living in the village. As a woman who lived under the apartheid system, she exposes how societies marginalise and silence the voices of women from culture to the apartheid government in this case.

\section{Mrs Konile's testimony Scene two: The dream about a goat}

The retranslation is as follows:

'We [Mrs Konile and her friend accompanying her] went and came back from the grant office. I said to her, the one I was going with, I said, Heyi! You know what, my hearts palpitating with a strange feeling [after having seen Pheza who lives in Cape Town, but is suddenly in Indwe] and it persists. Last night I had a dream a bad dream. I dreamt that here at the door there was a goat that was standing, like this [gesturing], ehh standing like this [gesturing with her hands], and my friend laughed and said, Eyi! You really had a bad dream. Next to the tree.'

In the official version, the word 'dream' was missing. Only the words '... a very scary period appeared continued, there was this-this was this goat looking up [sic]'. 'Indwe' was missing and now 'dream' was also missing, but 'very scary period' and 'there was this goat' also appeared. These missing words totally confused the audience. Moreover, the audience had expected Mrs Konile to speak about the treacherous day of her son's death and to portray him as a hero of the struggle against apartheid like all the mothers who had testified before her. The other three mothers gave powerful testimonies about how they learnt through television, comrades and neighbours that the police forces murdered their sons. Mrs Konile was expected to do the same. Remember Dr Boraine asked her '... tell us about what happened in 1986'. Instead of responding to this, Mrs Konile spoke about goats, made exclamations and gestures. No wonder the audience assumed she was psychologically traumatised, while others thought she was hallucinating, and others thought she was incapable of articulating herself; she was incomprehensible.

Mpolweni (2008:222) argues that a careful reading of the dream about the goat revealed that Mrs Konile was giving an account of how she learnt about her son's death. She articulated her own story in a way that rural traditional people do. So, to answer the question, 'how did you find out about your son's death', Mrs Konile created a dramatic story that was linked by dreams about the goat, strange feelings, gestures and exclamations, including the presence of Pheza in the village. In the Isixhosa religious cultural background, goats are used for rituals; however, when one dreams of a goat, it is considered a bad omen. It signals that there is something that has gone totally wrong. Mrs Konile used the dream about the goat to fit her testimony to the testimonies (see above 2.1) of the other three mothers who testified before her at the TRC. The other mothers dramatised their testimonies and told the TRC that they found out about their son's killings from television, from comrades and from their madams (2009:10). Though, Krog et al. (2009) write that:

Mrs Konile was not, however, very successful in steering her story within this four-tiered context. She chose to tell her story in a particular cultural and metaphoric way that sat strangely among the other narratives from the mothers of the Gugulethu Seven. (p. 86)

However, Mrs Konile is a village woman and it should have been obvious for the TRC that her storytelling would be different from the other three women from Cape Town. Her storytelling would also be different in style. Mrs Konile comes from an oral traditional background that utilises gestures, repetitions, direct speech and exclamations to get her narrative to the audience. But how could the TRC have known this when in the testimony, the place where Mrs Konile was from was missing.

This article seeks to emphasise that the narrative of 'the goat' in Mrs Konile's narrative has significance. The goat is not just an animal used for rituals in the isiXhosa religion and culture. To dream about a goat is a loaded statement; loaded with cultural connotations. If one reads the above-translated testimony, one would realise that when Pheza arrived in the village, the dream about the goat began to gain momentum. In the isiXhosa, religious culture to dream about a goat 
standing near the door or inside the house is considered bad. It means either something has gone totally wrong or something is about to go wrong.

Based on the previous discussion, I want to argue that Mrs Konile tried to suggest to the TRC that she did not find out about her son's death from neighbours, employees or television. But she linked dreams about the goat, heart palpitating with a strange feeling and the arrival of Pheza in the village. She knew something had gone wrong and it was related to her children and therefore she pushed Pheza to tell her what is wrong. If we consider this, we would see that Mrs Konile still followed the TRC's narrative but in her own way of storytelling and used religious cultural symbols to tell it. It the context of the TRC, where Desmond Tutu announced that 'in the new democratic South Africa, everyone, everything, belongs. None is an outsider, all are insiders and all belong', one would expect a better reception of Mrs Konile's testimony. If, truly, the TRC embraced the 'rainbow' notion, the TRC would have realised that Mrs Konile was a mother from rural areas and was closely connected to a traditional way of life. Mrs Konile was so alienated by the TRC processes that she was not able to speak to the processes and the processes were not able to get through to her. Mrs Konile's experiences, her disposition, her orientation and her worldview exposed the weaknesses of the TRC testimony model.

\section{Scene three: I remembered my son's feet when he was young}

'I met the comrades whom I was not familiar with. I was then introduced to the other mothers who lost their son's in the killing. We went to a meeting where they said that our sons were in a certain forest, when they were killed. It was said that our sons were asking for forgiveness when they were allegedly killed by the security forces members. After the meeting, we went to the mortuary to identify our sons. My son's body was so swollen covered with blood that I could not recognize him. The only way I recognised him was with the ... I remembered my son's feet when he was young. After we identified our sons we were told that we need to bury them, the 'Boers' said we must take our sons and bury them. I did not want to bury my son in Cape Town; I asked to go home with him. They denied me this and said Zabonke had bombs with him. The comrades also said he needed to be buried where he died. I gave up and went home to struggle with life on my own.'

There is not enough space here to go into depth about the many cross-cutting struggles of language (notion of multilingualism) except to say that after watching the video from the archives, I realised both the translator and the interpreter alike in the first and second scene misinterpret Mrs Konile (Krog \& Mpolweni 2009:222). Mrs Konile could not pronounce words such as comrade (ikhombresi), mortuary (moshani), graveyard (emalindeni) (note that in the translation above these words are translated correctly). As an uneducated woman, she used either Xhosa words to describe what she

8.Antjie Krog indicates that for her to be able to understand Mrs Konile's testimony, Mpolweni and Kopano translated the testimony to isiXhosa, and the IsiXhosa Mpolweni and Kopano translated the testimony to isiXhosa, and the IsiXhosa
religious background and the cultural and psychological practices restored the coherency, sensibility and dignity of Mrs Konile (Krog et al. 2009:85). was saying or a slang used in the rural environment (Mpolweni 2008). ${ }^{9}$ Perhaps what is important to say in this scene is that for the first time Mrs Konile finds herself in an emotional state or sentimental state about her son:

My son's body was so swollen covered with blood that I could not recognize him. The only way I recognised him was with the ... I remembered my son's feet when he was young. (p. 222)

\section{Scene 4: 'Eyi! Akusenzima! (Eyi its tough)'}

'I went home to collect coal and sustain my life. While I was collecting coal, a rock hit me. I was taken to hospital. At the hospital, the doctor identified me as the mother of Zabonke (her son), a terrorist. The doctor then chased me away. The doctor said go back under the rocks, you are not human that is where you belong.'

This part of the testimony Mrs Konile began by sighing heavenly six times within five rather short sentences. Moreover, when the TRC officials asked 'What would you say to the perpetrators?', Mrs Konile's said 'I would say nothing; they have put me in this state; I will just accept anything'. 'Eyi! Akusenzima! (Eyi it's tough)'. I want to suggest that in this part of the testimony, Mrs Konile completely leaves the TRC narrative structure in my own view on reconciliation and forgiveness. ${ }^{10}$ Like other mothers of the Gugulethu Seven, Mrs Konile was expected to forgive her son's killers and reconcile with them. Krog et al. (2009:125) argue that 'it was not that we felt she had to forgive, but we wanted to know how reasoned this around the concept of Ubuntu'. This suggests that the scholars were troubled by Mrs Konile's refusal of forgiveness and reconciliation; it suggested the refusal of Ubuntu:

The Ubuntu approach to truth and reconciliation, predicted on the belief that 'I am because we are', recognises the value of dialogue as part of transitional justice efforts in post-conflict regions. This approach was evident in the testimonies of women who had experienced trauma or lost loved ones. Their ability to forgive perpetrators was possible because of their recognition of the humanity of the perpetrator. (Godobo-Madikizela 2005:32)

Against this, this article acknowledges Mrs Konile's attitude towards reconciliation and forgiveness and the kind of Ubuntu that was being established at the TRC. I want to argue that Mrs Konile's refusal to offer forgiveness to perpetrators of gross human rights violations was her way of showing the TRC's inconsistencies. The TRC had been declared as a victim-driven process. However, perpetrators were the ones who were safe guarded from prosecution without statements of regret or remorse or some form of compensation provided for the victims of their deeds

\footnotetext{
9.Mpolweni (2008:222) writes that Riess (2000:9) in his reflection on the difficulties at the proceedings of the TRC was able to enter into another person's thought process and be able to rebuild his and/or her whole perspective in all its particularity. Secondly, the interpreters had to juggle with languages in order to fall in line with the notion of multilingualism which came into existence after the transition to democratic South Africa in 1994.

10. Remember: The TRC victim's narrative was that victims should give biographical details, which then leads to the middle part of the testimony about the circumstances and content of the violation, thereafter the desire and needs of the victim would be established, after this establishment then the commissioner who was chairing that specific evidence gathering would conclude the interaction (Krog 2007:191)
} 
(Chapman 2007:51-69; Govier \& Verwoerd 2002a:67-82; 2002b:178-205).

In this article, I want to argue that testimonies like Mrs Konile's that refused to play into the TRC's narrative of Ubuntu need to be revisited. The TRC obscured the meaning of Ubuntu from an African philosophy or ethic that encompasses justice, forgiveness, reconciliation, compassion, etc. To only be about forgiveness, I want to argue that Mrs Konile's refusal to forgiveness and reconciliation is a way that she questions the TRC: 'what sort of Ubuntu is this?' Mrs Konile argues that the 'Doctor said go back under the rocks, you are not human that is where you belong'. When she is asked if she would forgive, she declares 'I would say nothing; they have put me in this state; I will just accept anything, "Eyi! Akusenzima! (Eyi it's tough)"". ${ }^{11}$ One can argue that Mrs Konile is not able to recognise how forgiveness and reconciliation will restore her dignity as a human being, her well-being and her will to flourish in life as a human (to take her from nonbeing to being 'Ubuntu').

Again, 'I will just accept anything. "Eyi! Akusenzima! (Eyi it's tough)"', obviously shows how Mrs Konile needed some form of justice in her life at that time; she had lost her only son whom she was dependent on, she was an old woman, rural and uneducated, and she had no means of living a flourishing life in the new South Africa. Compensation would have made sense even if it was not going to bring her son back.

Eyi, kunzima [it's tough] has come to characterise the struggles of a new generation of South African activists known as the Fallist generation. Like Mrs Konile, the fallist generation has come to question concepts such as rainbow, Ubuntu, forgiveness and reconciliation post-apartheid. And like Mrs Konile, the new generation of leaders refer to the conditions of being black people in the new South Africa. I believe that Mrs Konile intentionally disrupts the TRC narrative by creating for the audience a dramatic narrative of her life which for others 'got lost in dreams about a goat, hit by a rock, exclamations, gestures', but to her it was a way of bringing to the fore the suffering she had endured when she lost her son. Her whole well-being was linked to her son, for her to flourish in life she needed her son. Mrs Konile through her testimony dared to speak against a system that continues to oppress so many women in the current South Africa. She dared to ask the question how can I forgive when so much has been taken from me? She dared to ask the question what is forgiveness when it is tough Eyi! Kunzima.

Mrs Konile's testimony is a case of an African black woman who challenges the view that women at the TRC of South Africa were content in speaking about the experiences of others and that they were comfortable to take on the duty of speaking out in order to engage others and on behalf of

11.I went home to collect coal to sustain life'. By the way people thought she was really incoherent here because in the first scene everyone assumed she was from Cape Town. Therefore, collecting coal is impossible in Cape Town. Cape Town does not have any mineral mines, but only has agricultural resources. However, if the word Indwe was written instead of indistinct, it would have made sense. There is information that at Indwe there was a place where people collected coal back in the days; however, how true is this I cannot verify for now. others (see Godobo-Madikizela 2005). Indeed, the TRC itself determined who belonged, which stories belonged and did not belong at the proceedings of the TRC of South Africa. However, Mrs Konile disrupts this narrative structure by telling her own story as a woman who lived under the apartheid system. She jeopardised the narrative of her son's courage and triumph over evil that the TRC wanted to hear, and instead, she opts to articulate her own suffering, struggles and what her son meant to her as a black woman who lived under the apartheid system. In this way she challenges the whole argument that women at the TRC of South Africa were content in speaking about the experiences of others and that they were comfortable to take on the duty of speaking out in order to engage others and on behalf of others.

\section{Concluding remarks}

Many scholars have argued that the construction of storytelling or processes of the TRC created controversy in terms of finding the truth. These scholars argue that the controversy had the potential to negatively affect the weight that was to be given to testimonies that did not adhere to the TRC's grid of intelligibility (see Mamdani, Maluleke, Andre du Toit, Richard Smith and others). Mrs Konile's testimony falls into these testimonies that did not adhere to the TRC's grid of intelligibility. As we can see from the above discussion, Mrs Konile did not fail to effectively narrate her story, but the TRC failed to hear her story. The TRC was looking for a certain kind of story: that of a brutal regime, heroic struggle by human spirit for truth and freedom and eventually triumph over evil. She was to portray her son as a hero and to show how resilient and how forgiving she was. But Mrs Konile in her way of story-telling refused to follow the TRC's narrative structure. To portray her son as a hero, Mrs Konile connected her well-being to that of her son. She shows the TRC that her son was her only way of flourishing as a woman living under the apartheid system. In the first scene where she speaks about being a widow, how she was dependent on her son and that she could not even receive land without her son, she exposes a system and a culture that did not recognise her as a human being. ${ }^{12}$

The fact that she stood firm and voiced out gender injustices in a time when most women were cautious of speaking about their 'private' suffering, experiences afford her recognition in gender studies, especially when we speak about gender and decolonisation. We need Mrs Konile's testimony because when she presented her own personal suffering at the TRC, she made invisible testimonies visible at the TRC. By telling her own experiences and suffering, she enabled women to stake their historical claims in South Africa.

Young (2012:118) argues that Mrs Konile's response to forgiveness and reconciliation is as if she comprehended or

12. She mourns this and argues all other people received land but she could not. And it seems to me she believes that the only reason she did not get the land was because she was a widow and her son was not visible to the villagers, and without a visible son in the isiXhosa culture, it means the villagers could do whatever they a visible son in the isiXhosa culture, it means the villagers could do whatever they
pleased. Here she exposes how structures within the village and her son determined her will to arise and flourish as a woman living in the village. 
recognised the TRC process inconsistencies, its rigidity as an institution and its insistence on a particular framework that has forgiveness and reconciliation as its end point. Mrs Konile resisted the imposed framework in her mind, and she resisted easy reading of her testimony. It is as if she heard the gender activists in the discussions held before the TRC that there is no man who can be liberated if women are not. With her power and control of her speech, she articulated a story of many women who suffered under the apartheid system. She dared to expose wounds that remain untold in the new South Africa, the wounds of structures and injustices.

\section{Acknowledgements \\ Competing interests}

The author declares that he has no financial or personal relationships which may have inappropriately influenced him in writing this article.

\section{References}

Chapman, A.R., 2007, 'Truth commission and intergroup forgiveness: The case of the South African Truth and Reconciliation Commission', Peace and Conflict: Journal of Peace and Psychology 13(1), 51-69. https://doi.org/10.1037/h0094024

Doxtader, E., \& Salazar P., 2007, Truth and Reconciliation in South Africa, Institute for Justice and Reconciliation, Claremont, viewed n.d., from http://www.oswego. edu/ jayaward/GLS\%20TRCintro.pdf

Godobo-Madikizela, P., 2005, Women's contributions to South African Truth and Reconciliation Commission, Hunt Alternatives Fund, Cambridge.
Govier, T. \& Verwoerd, W., 2002a, 'The promise and the pitfalls of apology', Journal of Philosophy of Social Sciences 33(1), 67-82. https://doi.org/10.1111/1467-9833.00124

Govier, T. \& Verwoerd, W., 2002b, 'Trust and the problem of national reconciliation', Journal of Philosophy of Social Sciences 32(2), 178-205. https://doi.org/ 10.1177/004931032002003

Imathiu, R.G., 2001, 'Circle transformative biblical narratives', in N.J Njoroge \& M.W. Dube (eds.), Thalitha cum: Theologies of African women, pp. 12-27, Custer Publications, Pietermaritzburg.

Krog, A., Mpolweni, N. \& Ratele, K., 2009, There was this goat. Investigating the Truth and Reconciliation Commission Testimony of Notrosse Nobomvu Konile, UKZN Press, Pietermaritzburg.

Krog, A. \& Mpolweni, N., 2009, 'Archived Voices: Refiguring Three Women's testimonies delivered to the South African Truth and Reconciliation Commission' Tulsa Studies in Women's Literature 28 (2), 357-374, viewed n.d., from https:// www.jstor.org/stable/pdf/40783424.pdf

Letsoalo, E., 1986, 'The Changing role Women in employment', in B. Thagale \& I. Masola (eds.), Hammering swords into ploughshares: Essay in honor of archbishop Mpilo Desmond Tutu, pp. 225-231, Skotaville Publishers, Johannesburg.

Mckay, S., 2000, 'Gender justice and reconciliation', Women's Studies International Forum 23(5), 561-570.

Meintjes, S., 2004, “'Gendered truth"'? Legacies of the South African Truth and Reconciliation Commission pages experiences', African Journal on Conflict Resolution 9(2), 101-107, viewed n.d., from https://journals.co.za/content/ accordr/9/2/EJC16350

Mpolweni, L. N., 2008, 'The importance of the original: challenges in interpreting a Xhosa testimony before the South African TRC', Journal of Multicultural Discourse 3(3), 221-232. https://doi.org/10.1080/17447140802372770

Olckers, I., 1996, 'Gender neutral truth - A reality shamefully distorted', Agenda 31, 61-67. https://doi.org/10.2307/4066266

Phiri, I.A., 2005, 'The circle for concerned African women theologians', The Ecumenical Review 57, 34-41. https://doi.org/10.1111/j.1758-6623.2005.tb00216.x

Tutu, D.M., 1994, The rainbow people of God: A spiritual journey from apartheid to Freedom, Rider, London.

Tutu, D.M., 1999, No future without forgiveness, Rider, London.

Young, S., 2012, 'Hospitality in a post-apartheid archive: Reflections on there was this goat and the challenge of alterity', Research in African Literatures, 43, 115-137. https://doi.org/10.2979/reseafrilite.43.2.115 